\title{
RECENSIÓN
}

\section{Michael S. Gazzaniga, El instinto de la conciencia. Cómo el cerebro crea la mente, Barcelona: Paidós, 2019 (344 págs.)}

Si bien es cierto que la cuestión de la conciencia ha sido manida en diversos estudios, la principal relevancia de la obra de Gazzaniga estriba en su carácter analítico y en la idea de diferentes tipos de conciencia según el hemisferio cerebral que rija. Mediante la profusión teórica y argumentativa — tres partes que recogen la decena de capítulosel autor suscita el interés lector, dado que se produce la incursión de incógnitas neurológicas presumiblemente desconocidas, algo que finalmente nos conduce a aseverar la maleabilidad teórica, esto es, múltiples factores que operan y generan la conciencia "personal y privada" (De la Fuente, 2002).

Ya en el proemio (pp. 1-11) se explicita esta variabilidad que da paso a la primera parte, "El camino hacia el pensamiento moderno" (pp. 21-75), que contiene la tríada de los capítulos iniciales, todos ellos de corte histórico-filosófico. Concretamente en el capítulo primero, "La rígida inestable y necia concepción histórica de la conciencia" (pp. 21-41), Gazzaniga realiza un análisis sociocultural y enfatiza en el binomio mente/cuerpo el método trabajado por el conspicuo filósofo Descartes, que ineludiblemente ha sido una constante a lo largo de la historia. Análogamente, resulta especialmente atractiva la consabida teoría causal de Aristóteles, algo que, sostiene Gazzaniga, no ha estado exento de controversia, puesto que "[...] saber cómo construir algo no implica entender cómo funciona; y viceversa $[\ldots]^{\prime \prime}($ p. 26).

Subsecuentemente, el segundo capítulo, "Los albores del pensamiento empírico en filosofía" (pp. 43-73), prosigue con la fundamentación filosófica a tenor de la evolución de la conciencia y apostilla la relevancia de Wilhelm Wundt mediante sus contribuciones a la psicología experimental, lo que permitió engrosar los conocimientos al respecto de la conciencia y de lo que la misma suponía para los seres humanos; algo que establece ilación con el tercer capítulo, "Los grandes progresos del siglo xx y los inicios del pensamiento moderno", (pp. 75-105), capítulo idiosincrático, dado que en él trata el viso diferenciador de la conciencia según el hemisferio que opere. 
Así las cosas, esta teoría se torna el argumento central de la obra, que prosigue en el capítulo cuarto, "Cómo fabricar cerebros módulo a módulo" (pp. 109-139), inserto en la segunda parte, "El sistema físico" (pp. 109-175), en el que asevera que el cerebro opera al unísono y por ello ocurren los procesos mentales y los comportamientos. No obstante, resulta especialmente destacable el hecho de que, pese a que se produzcan lesiones cerebrales en determinados individuos, estas no vayan en detrimento de la conciencia.

Al hilo de ello, el quinto capítulo, "Empezamos a entender la arquitectura cerebral" (pp. 141-173), ratifica la idea de modularidad como modo de estratificación en la evolución cerebral, ergo principio clave en el proceso de cognición. Así las cosas, en el sexto capítulo, "El abuelo está demente, pero conserva la conciencia" (pp. 175-200), el autor recupera la idea de que existen sistemas entramados que preservan las emociones básicas; algo que se relaciona con la teoría de la complementariedad, íntimamente vinculada a la causalidad, entendida como el concepto afectante en la evolución temporal de un estado (Castellà, 2015). Ello es tratado con profusión en el capítulo séptimo, "El concepto de complementariedad: el regalo de la física" (pp. 203-226), que da paso a la tercera parte de la obra, "Llega la conciencia" (pp. 203-285). En dicho capítulo toma la anterior premisa como modo de relacionar el cerebro con la mente y cavilar en torno a sus manifestaciones.

Seguidamente, en el capítulo octavo, "De lo no viviente a lo viviente y de las neuronas a la mente" (pp. 227-256), queda patente tal relación entre la mente y el cerebro, la escisión de los cuales es la causante de las desigualdades entre lo viviente y lo no viviente, algo en lo que también se hace alusión a los códigos y signos que presentan los sistemas vivientes. A continuación, mediante el capítulo noveno, "Torrentes de burbujas y conciencia personal" (pp. 257, 284), el autor procura explicar la extensión de la conciencia, algo que subraya como complejo e irreductible en el décimo capítulo, "La conciencia es un instinto" (pp. 285-299), manifestando pues que los instintos obedecen a estratos presentes en la dimensión física. Es por ello que la aprehensión de los instintos trae consigo la percepción de la conciencia. En este orden de cosas, Gazzaniga concluye con una afirmación a priori baladí: la conciencia se resume en instinto. Como colofón, el autor destina los apartados que siguen: agradecimientos (p. 301), notas (p. 305) e índice onomástico y de materias.

En suma, pese al encomio que merece una obra de estas características, resulta palmaria la vastedad de la misma, presumiblemente la incursión de extensos capítulos consistentes fundamentalmente en un volcado de información resulta ambigua: la magnitud del campo de estudio es innegable y, pese a que sean elementos primordiales en la vertebración, es algo embrollado en su exposición. 


\section{REFERENCIAS BIBLIOGRÁFICAS}

Castellà, J. (2015). "La aparición de la noción de complementariedad de Bohr y su extensión más allá de la Físisca". En Revista Internacional de Ciencias Humanas, 4 (2): 305-314.

De la Fuente, R. (2002). "El estudio de la conciencia: estado actual”. En Salud Mental, 25 (5): $1-9$.

Irene Alfaro Cremades

Universitat Jaume I, Castellón, España

al388217@uji.es 